\title{
The rarest tortoise on earth
}

David Curl

The Madagascan tortoise Geochelone from the Oryx 100\% Fund, the author, yniphora, known locally as the 'angonoka', is together with lan Scoones, Mike Guy and found only near isolated patches of bamboo Gilbert Rakotoarisoa, has recently carried out forest in the vicinity of Baly Bay in north- a survey of the area. In this article, he western Madagascar. As part of an Oxford discusses the conservation of this highly University Expedition, and with some help endangered animal.

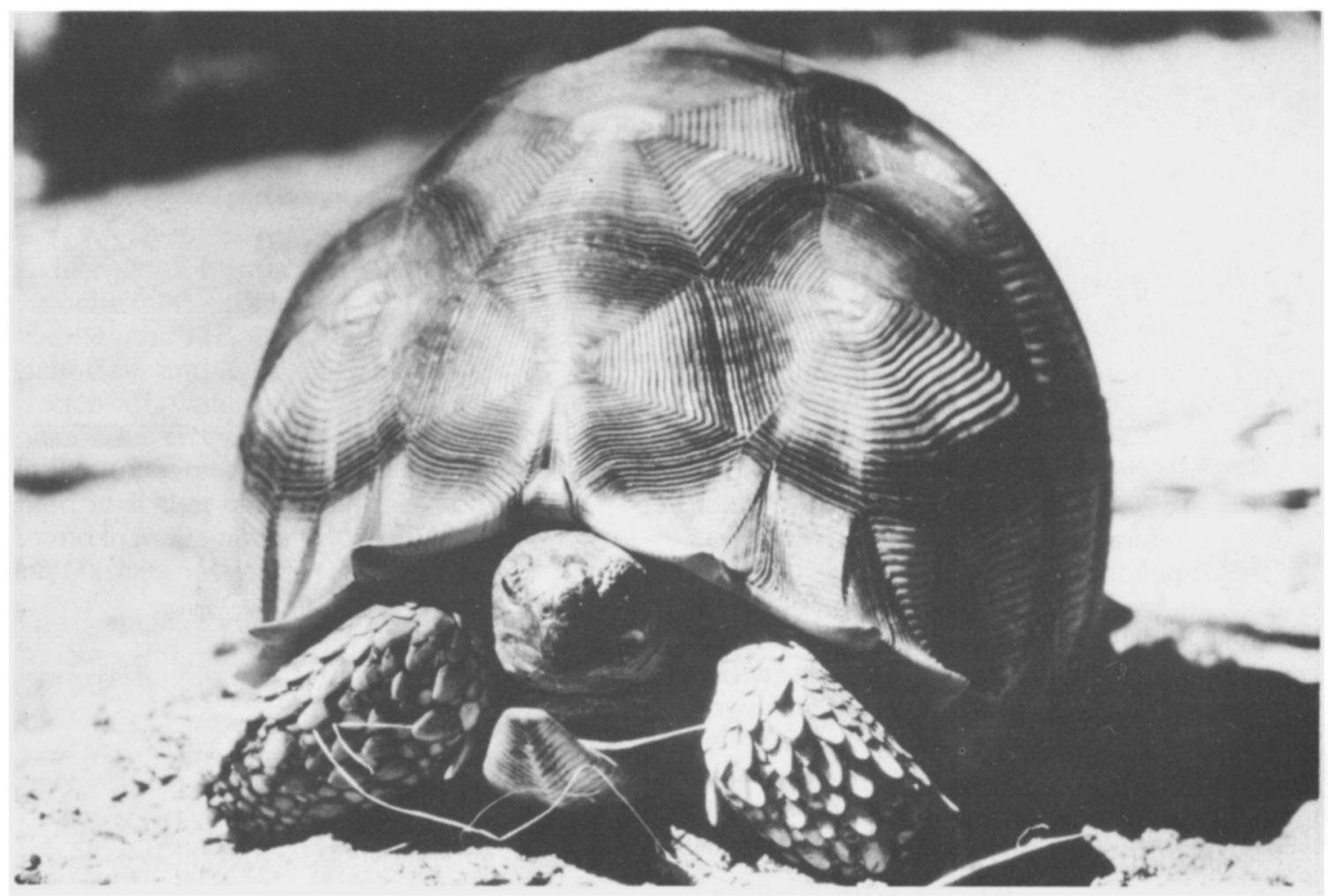

The angonoka, or angulated tortoise (David Curl). 
One hundred years after its first description by Vaillant in 1885, the angonoka Geochelone yniphora is now believed to be the world's rarest tortoise. It was not until the turn of the century that its natural location, in north-western Madagascar, was discovered (Siebenrock, 1903), and since then little has been written about the tortoise. A few visits to Baly Bay in the early/mid1970s gave little cause for optimism and, as a result, a total population estimate of between a few dozen and 100 animals was made (IUCN/ SSC Tortoise Specialist Group, 1982). In order to help draw up a conservation programme, we carried out a survey in August and September 1983 , and the results of this were made available to the Madagascan authorities early in 1984. In the meantime, the International Union for Conservation of Nature and Natural Resources
(IUCN) has declared the tortoise to be one of the 12 rarest animals on earth.

\section{Distribution}

Today, there are five different tortoises to be found in Madagascar. The hinged tortoise Kinixys belliana may well have been brought over from the African mainland in comparatively recent times, but the remaining four species have been evolving in isolation for millions of years. Changes in the country's vegetation, especially since the first settlers arrived some 1500 years ago, have left these four endemic species with extremely limited distributions-none more so than the angonoka, which is now restricted mainly to an area of some $25 \mathrm{~km}$ by $60 \mathrm{~km}$ around Baly Bay.

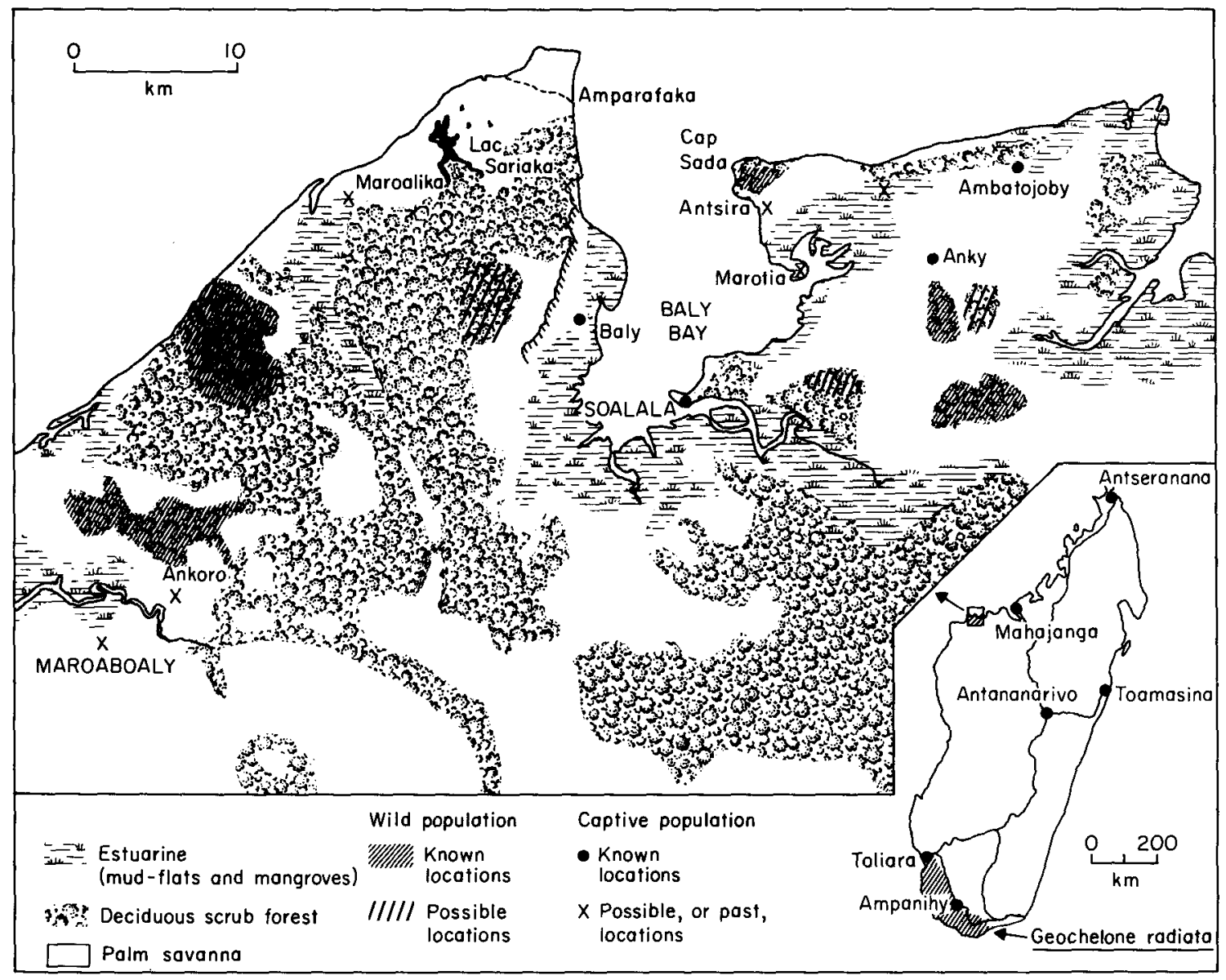

The locations of Geochelone yniphora around Baly Bay. 


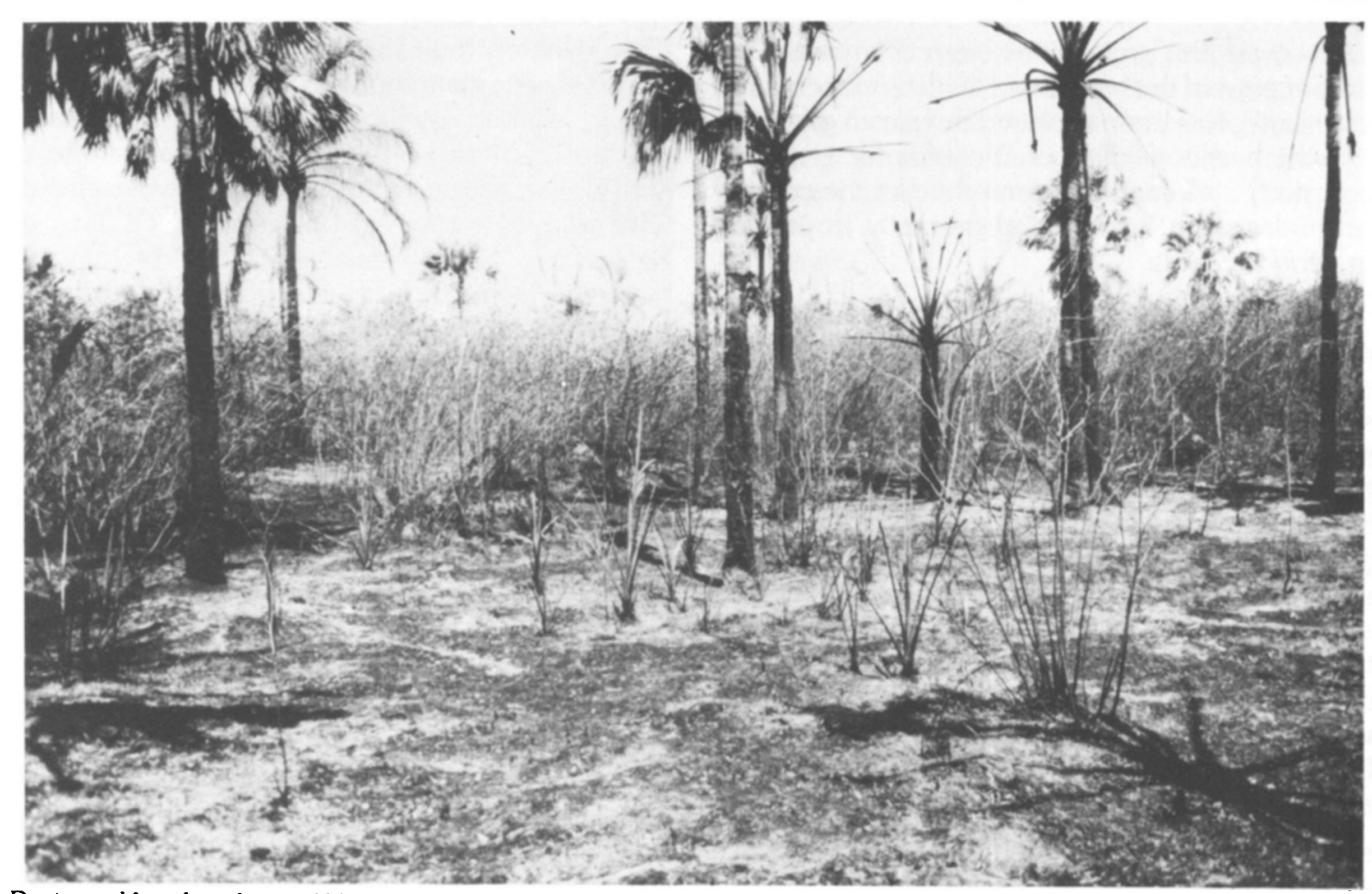

Destroyed bamboo forest. Although regeneration may be rapid, frequent fires can result in the depletion, if not eradication, of the small, isolated populations of the tortoise that still remain (David Curl).

Aldabra atoll, home of the Aldabran giant tortoise Geochelone gigantea (or Dipsochelys elephantina!) (Bour, 1982), lies $500 \mathrm{~km}$ north of Baly Bay, and it may well have been across this stretch of water that its ancestors made the hazardous crossing to a number of islands in the Indian Ocean. The hand of man, however, has seen to it that giant tortoises can no longer be found in Madagascar or on any of the neighbouring Mascarene islands.

The habitat and climate around Baly Bay, of course, differs considerably from that of these oceanic islands. Although little rain falls between May and October, the wet season brings with it many cyclones and, even since our visit, the village of Mitsinjo-where we first encountered captive tortoises-has been destroyed (and almost as quickly rebuilt) with the passing of cyclone 'Kamisy'.

Three distinct vegetation types can be recognized in this region: mangroves, dry deciduous forest and extensive stretches of palm savanna. It is at Rarest tortoise on earth the boundary between the forest and the savanna that the angonoka seems to live. In particular, it can be found in the bamboo and secondary forests that grade into more open grassland, and, with our estimate of between 40 and $80 \mathrm{sq} \mathrm{km}$ of suitable habitat in the area, there may be as few as $100-400$ tortoises left in the wild. Despite this low figure, and the fragmented nature of the surviving populations, individuals of all sizes can still be found; it appears, therefore, that breeding is still taking place in the wild with some success. Furthermore, although we travelled beyond the known range of the tortoise, there remains the possibility that a further outlying population may yet be discovered.

\section{Factors affecting the survival of G. yniphora}

\section{Habitat alteration}

The disappeareance of Madagascar's forests 
since man first arrived has been dramatic. Over 80 per cent of the woodland, which once covered the island, has been replaced by barren grassland to which the wildlife of the country is poorly adapted, and each year one-third of the country burns beneath fires started primarily to provide grazing for cattle.

Although the overall pattern of forest cover around Baly Bay itself has changed little in recent decades, during each dry season extensive fires sweep through the savanna and frequently spread into neighbouring areas of scrub and bamboo. While many species of tortoise are adapted to living in areas where fires are a natural part of succession, the effect on a population as small as that of the angonoka is particularly serious. Not only will many individuals die in a fire that passes slowly over their hide-outs, but the destruction of each patch of suitable habitat, which may take several years to regenerate, is likely to remove one more area from the tortoise's already limited distribution.

\section{Captivity}

Madagascar is perhaps unique among African countries in the extent to which pets are kept, and tortoises can be found in captivity in many parts of the country. Although $G$. yniphora is one of three tortoise species listed as endangered in The IUCN Amphibia-Reptilia Red Data Book (Groombridge, 1982), as well as in Appendix I of the Convention on International Trade in Endangered Species of Wild Fauna and Flora (CITES), pets may still be kept under certain conditions. Villagers are well aware of the annual cost of $3000 \mathrm{MGF}$ ( $£ 4.60$ ) that must be paid locally for each animal, and captive tortoises may be hidden from any investigating official.

The reasons for keeping pet tortoises vary considerably from village to village. The idea that a tortoise in your back-yard can ward off poultry diseases is now widespread in Soalala, the main village in the region, but possibly originated with the influx of people from the south of the country, where the closely related Geochelone radiata is also a popular pet. In other villages, tortoises may be kept for more western motives-for fun, or simply because they are considered attractive.
Our research indicates that there is a far greater number of captive tortoises in the region than had previously been suggested, and reliable estimates put the captive population of Soalala alone at 15-40 individuals. Although the collecting of wild animals is mainly opportunistic, it is likely to be having a significant effect on an already depleted population. Some 50 captive tortoises must exist in the Baly Bay area, and the fact that many of these are recent acquisitions implies either a fairly high tumover rate, or an increasing captive population. The former, in turn, suggests either that they are destined to be eaten, or that they suffer considerably reduced longevity under captive conditions, despite being well treated by their owners.

\section{Tortoises as food}

Tortoises have been a traditional source of food for many sailors in the Indian Ocean; being compact and able to look after themselves, they must, in fact, have been just about the first form of convenience food. Yet while this trade has undoubtedly affected the angonoka in historical times, one of the traditional taboos of the Sakalav people indigenous to the Baly Bay region prohibits the eating of land tortoises.

Recent years have seen an influx of people from different regions, and traditions are beginning to change. Some Sakalaus no longer refuse to eat tortoises and, instead, the influence of Islamic culture has brought with it taboos against the eating of wild pigs, themselves a serious threat to the tortoise. Fortunately, the angonoka remains a sporadic, and much less frequent, part of the local diet than do the four species of turtle (especially the green turtle Chelonia mydas) found offshore.

\section{Predation}

While adult tortoises are rarely killed by natural predators, the eggs and hatchlings of most species are particularly vulnerable. Potential predators of the angonoka include the constrictor Acrantophis madagascariensis, the kite Miluus migrans parasitus, several endemic mongoose-like viverrids, crows (Corvus spp.), and possibly even the crested wood ibis Lophotibis cristata (found throughout the region).

Oryx Vol 20 No 1, January 1986 


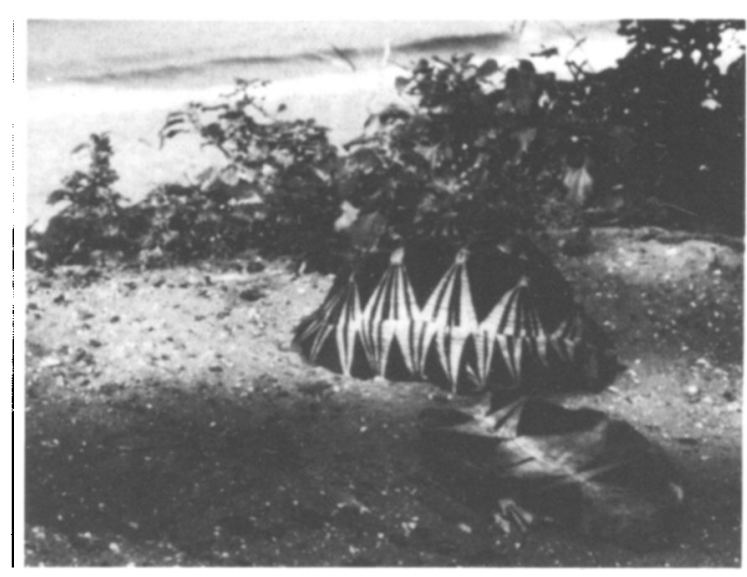

The empty carapace of a radiated tortoise Geochelone radiata on the beach. This species is widely eaten in the south of Madagascar (David Curl).

The most serious threat, however, appears to be the introduced African bush pig Potamochoerus porcus. Since it is rarely hunted, this species is now widespread around Baly Bay and, as the impact of wild pig predation on tortoise populations has been clearly documented by MacFarland et al. (1974) for the Galapagos giant tortoise Geochelone elephantopus, where both eggs and sizeable young are subject to heavy predation, it seems likely that this introduced predator is a major threat to the survival of the angonoka.

\section{Conservation measures}

Conservation measures for this rare reptile would involve three main approaches: setting up a reserve, captive breeding, and education. In a report compiled by Dr J. Juvik for the IUCN Tortoise Group (1982), the possiblity of a reserve at Cape Sada - at the north-eastern tip of Baly Bay-followed by the removal of any wild pigs, was discussed. From our own investigations, it seems that such a reserve would not be unpopular with the local villagers, who rarely visit the Cape, and involvement of those villagers who have assumed the responsibility of local 'policemen' would help to ensure the proper management of such a reserve.

The survival of a number of Madagascar's endemic reptiles may depend upon the setting up of a captive breeding facility within the country. Plans are currently being considered for the Rarest tortoise on earth initiation of a captive-breeding programme that would contribute to the survival prospects of at least the four endemic tortoise species, and, with the help of some Malagasy who have recently been gaining experience at Jersey Zoo, it is hoped that such a project may begin in the very near future.

At least as important, however, is a programme of conservation education; educational material, written in Malagasy, is currently being prepared for distribution and use in the country. The demand for captive tortoises could almost certainly be reduced by making poultry vaccine more widely available, while local awareness of the many threats to the tortoise is crucial if this intriguing animal is to survive.

Ultimately, though, in a country where the population is still rising exponentially, the survival of many of Madagascar's unique forms of wildlife depends upon the development of sustainable methods of agriculture that do not involve the destruction of further areas of forest.

Tortoises have been around on this planet since the age of the dinosaurs. With the immediate implementation of but a few conservation measures, there is every hope that even this rare animal may survive for many years to come.

\section{References}

Bour, R. 1982. Contribution à la connaissance des tortues terrestres des Seychelles; définition du genre endémique et description d'une espèce nouvelle probablement originaire des iles granitiques et au borde de l'extinction. Compr Rendu Hebd. Seanc. Acad. Sci, Paris, 295, 117-122.

Curl, D.A., Scoones, I.C., Guy, M.K. and Rakotoarisoa, G. 1985. The Madagascan tortoise Geochelone yniphora: current status and distribution. Biol. Conserv. 34, 35-54.

Groombridge, B. 1982. The IUCN Amphibia-Reptilia Red Data Book. Part I. Testudines, Crocodylia, Rhynchocephalia. IUCN, Gland, Switzerland.

IUCN/SSC Tortoise Specialist Group 1982. Revised Species Recovery Plan for the endangered Madagascan Angulated Tortoise (Geochelone $=$ Asterochelys yniphora). Unpubl. proposal.

MacFarland, C.G., Villa, J. and Toro, B. 1974. The Galapagos giant tortoises (Geochelone elephantopus). I. Status of the surviving populations. Biol. Conserv. 6, 118-133.

Siebenrock, R. 1903. Schildkröten von Madagaskar und Aldabra. Abhandl. Senckenb. Naturf. Gesellsch. 27, 241258.

Vaillant, L. 1885. Sur une tortue terrestre d'espèce nouvelle, rapportée par M. Humblot au Museum d'Histoire naturelle. Bull. Soc. Phil. Paris, 440-441.

D. A. Curl, Ecology Research Group, Rutherford College, The University, Canterbury, Kent CT2 7NX, UK. 